\title{
Major depression, fibromyalgia and labour force participation: A population-based cross-sectional study
} Aliya Kassam ${ }^{1}$ and Scott B Patten*2,3

\author{
Address: 'Section of Community Psychiatry, Health Services Research Department, Institute of Psychiatry, King's College London, UK, \\ ${ }^{2}$ Department of Community Health Sciences, University of Calgary, 3330 Hospital Drive NW, T2N 4N1, Calgary, AB, Canada and ${ }^{3}$ Department \\ of Psychiatry, University of Calgary, 1403 - 29 Street NW. Calgary, T2N 2T9, Canada \\ Email: Aliya Kassam - aliya.kassam@iop.kcl.ac.uk; Scott B Patten* - patten@ucalgary.ca \\ * Corresponding author
}

Published: 19 January 2006

BMC Musculoskeletal Disorders 2006, 7:4 doi:10.1 186/147|-2474-7-4

This article is available from: http://www.biomedcentral.com/147/-2474/7/4

(C) 2006 Kassam and Patten; licensee BioMed Central Ltd.

This is an Open Access article distributed under the terms of the Creative Commons Attribution License (http://creativecommons.org/licenses/by/2.0), which permits unrestricted use, distribution, and reproduction in any medium, provided the original work is properly cited.
Received: 18 July 2005

Accepted: 19 January 2006

\begin{abstract}
Background: Previous studies have documented an elevated frequency of depressive symptoms and disorders in fibromyalgia, but have not examined the association between this comorbidity and occupational status. The purpose of this study was to describe these epidemiological associations using a national probability sample.

Methods: Data from iteration I.I of the Canadian Community Health Survey (CCHS) were used. The CCHS I.I was a large-scale national general health survey. The prevalence of major depression in subjects reporting that they had been diagnosed with fibromyalgia by a health professional was estimated, and then stratified by demographic variables. Logistic regression models predicting labour force participation were also examined.

Results: The annual prevalence of major depression was three times higher in subjects with fibromyalgia: $22.2 \%(95 \% \mathrm{Cl} 19.4-24.9)$, than in those without this condition: $7.2 \%(95 \% \mathrm{Cl} 7.0-$ 7.4). The association persisted despite stratification for demographic variables. Logistic regression models predicting labour force participation indicated that both conditions had an independent (negative) effect on labour force participation.

Conclusion: Fibromyalgia and major depression commonly co-occur and may be related to each other at a pathophysiological level. However, each syndrome is independently and negatively associated with labour force participation. A strength of this study is that it was conducted in a large probability sample from the general population. The main limitations are its cross-sectional nature, and its reliance on self-reported diagnoses of fibromyalgia.
\end{abstract}

\section{Background}

Fibromyalgia is a syndrome of unknown etiology characterized by chronic widespread joint and muscle pain and by pain on palpation of tender points [1]. The literature contains several population-based prevalence estimates, which have generally fallen in the range of $1-3 \%[2-5]$. Chronic medical conditions are, in general, associated with an increased frequency of major depression [6-8], but the association with fibromyalgia may be particularly strong. One general population study reported an odds ratio of 2.85 for subjects with fibromyalgia equalling or exceeding a score of 4.0 on the depression scale of the Arthritis Impact Measurement Scales [2]. Another study, using the Present State Examination to detect ICD-10 
defined depressive disorders in a general population sample, reported a doubling of prevalence in subjects with chronic widespread pain [9].

Some studies have focussed on co-aggregation of these conditions in families [10], whereas other studies have examined possible pathophysiological linkages between depression and fibromyalgia. It has been reported, for example, that people with fibromyalgia have elevated levels of alexithymia and anger [11], that depression risk factors such as work stress [12] and childhood traumatic events [13] may contribute to fibromyalgia etiology, and that antidepressants are efficacious treatments for fibromyalgia [14]. Other studies have identified an influence of social support and emotional context on pain thresholds in fibromyalgia [15]. These results, and others, have caused some authors to conclude that there is an intrinsic connection, or perhaps on some level an equivalency, between depressive disorders and fibromyalgia [10,1618]. Other authors have conceptualized fibromyalgia and depressive disorders as members of a broad category of stress disorders [19].

Based on an analysis of case-control data, it has been argued that the comorbidity between mood disorders and fibromyalgia is an artefact of bias resulting from treatment-seeking behaviour [20]. This assertion highlights the importance of population-based data and the need to further characterise the epidemiology of this comorbidity in the general population. Epidemiological data are of considerable importance for describing and understanding public health problems. A study conducted in the United States using administrative health care and disability claims data compared the economic burden associated with co-morbid depression and fibromyalgia. It was found that mean employer payments per patient were $\$ 11,899, \$ 8,073$ and $\$ 5,163$ for employees with co-morbid depression and fibromyalgia, depression alone, and fibromyalgia alone, compared to $\$ 2,486$ for the total sample [21]. These results suggest that the two conditions may have effects that are independent in the multiplicative sense: the two conditions alone increased costs by a factor of $2-3$, and in combination by an amount resembling the product of these increases.

One objective of this study was to describe the association between co-morbid depression and fibromyalgia in the general population in more detail than has been done previously. Another objective was to examine major depression-fibromyalgia comorbidity in relation to a key functional outcome: labour force participation.

\section{Methods}

The data source for this study was the Canadian Community Health Survey (CCHS), iteration 1.1, a cross-sectional general health survey of household residents conducted by Statistics Canada (the Canadian Government's national statistical agency) in 2000 and 2001. The sample size for the CCHS 1.1 was 131,535 subjects aged 12 years and older. However, as the instrument used to identify depressive episodes has not been validated in adolescents, we restricted the current analysis to subjects 18 years and older, $\mathrm{n}=115,160$.

The Composite International Diagnostic Interview (CIDI) short form for major depression (CIDI-SFMD) [8] was used to identify episodes of major depression in this survey. The CIDI-SFMD is a brief version of the CIDI diagnostic interview. Five or more of the DSM-IV-TR symptombased criteria for major depression (at least one of which must be depressed mood or loss of interest) were required. According to the CIDI-SFMD validation data, this would result in a $90 \%$ positive predictive value for DSM-IV major depression [9].

The CCHS 1.1 also collected self-report diagnostic information about chronic medical conditions. In each case, survey items enquired about the presence of long-term medical conditions that had been "diagnosed by a health professional." One of the conditions evaluated was fibromyalgia. The CCHS 1.1 also included items evaluating labour force participation. As subjects over the age of 75 are unlikely to be members of the labour force, analyses of this variable excluded subjects over the age of 75 . The sample size for this part of the analysis was 105,538 .

Household income was dichotomized after adjustment for the number of people in each [22]. Lowest and lowermiddle income categories were collapsed into a "low income" group and upper-middle and highest income quartiles were grouped into a "high income" group. Education was dichotomized into a "low education" group that included high school graduation or less and a "high education" group containing those with at least some post secondary education. Marital status was classified using two categories: those who were married/common-law were placed into a "married" category and those who were single (never married), widowed, separated and divorced comprising the "unmarried" group.

Analysis was conducted using $\mathrm{SAS}^{\circledast}$ version 8.0. Due to multi-staged sampling procedures, unequal selection probabilities and non-response, sampling weights adjusting for these factors were used in the analysis. A bootstrap variance estimation procedure was used for statistical analysis of the weighted estimates.

\section{Results}

The CCHS achieved a 91.4\% household response rate, and a $91.9 \%$ individual-respondent response rate. This 
Table I: Demographic \& Clinical Features of the Sample.

\begin{tabular}{|c|c|c|c|c|c|}
\hline & & \multicolumn{2}{|c|}{ Sample Characteristics } & \multicolumn{2}{|c|}{ Prevalence $(95 \% \mathrm{Cl})$} \\
\hline & & Unweighted n (\%) & Weighted \% & Fibromyalgia \% & Major Depression \% \\
\hline \multirow[t]{2}{*}{ Sex } & Men & $52772(45.8)$ & 49.1 & $0.4(0.3-0.4)$ & $5.3(5.0-5.6)$ \\
\hline & Women & $62388(54.2)$ & 50.9 & $2.0(1.9-2.1)$ & $9.4(9.1-9.7)$ \\
\hline \multirow[t]{2}{*}{ Age } & 50 years + & $48707(42.3)$ & 36.5 & $1.7(1.5-1.9)$ & $4.9(4.6-5.2)$ \\
\hline & 18 to 49 & $66430(57.7)$ & 63.5 & $0.3(0.2-0.3)$ & $8.8(8.5-9.1)$ \\
\hline \multirow[t]{2}{*}{ Income* } & High & $8585 \mathrm{I}(80.6)$ & 86.8 & $1.0(0.9-1.1)$ & $6.5(6.2-6.7)$ \\
\hline & Low & $20626(19.4)$ & 13.2 & $1.5(1.3-1.7)$ & $9.7(9.3-10.1)$ \\
\hline \multirow[t]{2}{*}{ Education** } & High & $60986(53.5)$ & 57.1 & $1.2(1.0-1.3)$ & $7.2(6.9-7.4)$ \\
\hline & Low & $53008(46.5)$ & 42.9 & $1.3(1.1-1.4)$ & $7.7(7.4-8.0)$ \\
\hline \multirow[t]{2}{*}{ Marital Status **** } & Married & $66888(58.2)$ & 64.2 & $1.2(1.1-1.4)$ & $5.6(5.3-5.8)$ \\
\hline & Unmarried & $48113(41.8)$ & 35.8 & $1.1(1.0-1.3)$ & $10.7(|0.3-1| .1)$ \\
\hline Total & & $115137(100)$ & 100 & $1.2(1.1-1.3)$ & $7.4(7.2-7.6)$ \\
\hline
\end{tabular}

$*_{n}=106477$ because of missing income data from $7.5 \%$ of subjects.

$* * n=113994$ because of missing data from $1 \%$ of subjects.

**** $\mathrm{n}=|1| 500 \mid$ because of missing data from $0.1 \%$ of subjects.

resulted in a survey sample that was highly representative of the national target population, even before the application of sampling weights (see Table 1). Table 1 presents a description of the sample, and reproduces expected patterns of association. Fibromyalgia is significantly more common in women and in older age groups, whereas major depression is more common in women, in the younger age category and in unmarried subjects. Both major depression and fibromyalgia were more common in low income subjects.

The association between fibromyalgia and major depression may have been confounded by other variables that are associated with major depression. In order to explore this possibility, the prevalence of major depression in subjects with and without fibromyalgia was stratified by a set of demographic variables. As seen in Table 2, the prevalence of major depression was found to be consistently higher in those with fibromyalgia than in those without, irrespective of demographic category.
Non-participation in the labour force was reported by 40,630 subjects (weighted frequency estimate $35.0 \%$ ). A logistic regression model incorporating both major depression and fibromyalgia as predictors of labour force participation identified no interaction between these two variables (Wald Statistic $=0.17, \mathrm{p}=0.68$ ) suggesting an independent multiplicative contribution to the outcome, so the interaction term was removed from the model. Odds ratios were then estimated from the reduced model both for fibromyalgia (OR $=2.7,95 \%$ CI $2.3-3.2)$ and major depression $(\mathrm{OR}=1.4,95 \%$ CI $1.3-1.5)$.

In a series of additional analyses, the logistic regression model described above was expanded to include each of the demographic variables listed in Table 1, along with associated interaction terms. The associations between major depression and fibromyalgia remained significant in all of these models, and in no cases did major depression by fibromyalgia interactions emerge.

Table 2: Annual Major Depression Prevalence With and Without Fibromyalgia, Stratified by Demographic Variables

\begin{tabular}{|c|c|c|c|}
\hline & & $\begin{array}{l}\text { Prevalence in Subjects with } \\
\text { Fibromyalgia \% }(95 \% \mathrm{Cl})\end{array}$ & $\begin{array}{l}\text { Prevalence in Subjects without } \\
\text { Fibromyalgia } \%(95 \% \mathrm{Cl})\end{array}$ \\
\hline \multirow[t]{2}{*}{ Sex } & Men & $13.7(8.3-19.1)$ & $5.3(5.0-5.6)$ \\
\hline & Women & $23.6(20.6-26.7)$ & $9.1(8.8-9.4)$ \\
\hline \multirow[t]{2}{*}{ Age } & 50 years + & $15.0(11.9-18.1)$ & $4.9(4.6-5.2)$ \\
\hline & 18 to 49 & $29.9(25.4-34.5)$ & $8.8(8.5-9.1)$ \\
\hline \multirow{2}{*}{ Income } & High & $20.8(16.8-24.8)$ & $6.5(6.2-6.7)$ \\
\hline & Low & $27.1(22.7-31.4)$ & $9.7(9.3-10.1)$ \\
\hline \multirow[t]{2}{*}{ Education } & High & $24.2(20.2-28.2)$ & $7.2(6.9-7.4)$ \\
\hline & Low & $19.7(25.7-23.8)$ & $7.7(7.4-8.0)$ \\
\hline \multirow[t]{2}{*}{ Marital Status } & Married & $17.7(14.5-20.9)$ & $5.6(5.3-5.8)$ \\
\hline & Unmarried & $30.7(25.8-35.7)$ & $10.7(10.3-11.1)$ \\
\hline
\end{tabular}


Finally, the subset of respondents who reported that they were permanently disabled and unable to work was identified. The weighted estimate for this proportion was $2.6 \%$ $(95 \%$ CI $2.5-2.8)$ in the general population $(2.2 \%$ in those without major depression or fibromyalgia). Among subjects with major depression but not fibromyalgia, $5.7 \%(95 \%$ CI 4.9 - 6.5) fell into this category, as did $15.9 \%$ (95\% CI 12.2 - 19.6) of subjects with fibromyalgia but not major depression. In subjects with both conditions, $23.0 \%$ (95\% CI 15.2 - 30.9) fell into this category. Again a multiplicative pattern indicative of an independent effect is observed in the sense that an approximately 2fold and 5-fold increase in subjects with one of these conditions combines in the comorbid group to an approximately 10 fold increase over the baseline frequency.

A similar pattern was found when data from a more general item referring to restriction of activities (at work, at home or in other categories) due to a physical or mental health problems was examined. Subjects without major depression or fibromyalgia reported activity restrictions $10.0 \%$ of the time (95\% CI 9.7 - 10.2), having major depression alone increased this to $20.0 \%$ (95\% CI 18.7 21.5 ), fibromyalgia alone to $28.4 \%$ (95\% CI $32.3-41.4$ ) and both conditions together to $57.6 \%$ (95\% CI 48.5 66.8).

\section{Discussion}

A strong association between fibromyalgia and major depression was observed in this study, and it remained evident after stratification for sex, age, marital status, education and income. This finding replicates and solidifies earlier results. One of the previous studies used a depressive symptom measure, rather than a diagnostic instrument [2] and another used ICD-10 criteria for depression and the concept of chronic widespread pain was used rather than a fibromyalgia diagnosis [9]. It is worth noting that chronic pain in general is associated with depression, and that pain and depression may be linked through a variety of biological mechanisms, see review [23]. From the perspective of labour force participation, subjects with either or both of these conditions are less likely to be participating in the workforce. They appear to have an independent effect on the probability of workforce participation.

While the large sample size of the CCHS is advantageous for statistical analysis, the use of such data is subject to limitations. As a general health survey, the CCHS uses a variety of brief measures. Both the major depression measure (CIDI-SFMD) and the self-report of fibromyalgia may be subject to error. For this reason, the findings should be replicated in studies using more detailed measures. Because the data source for this study was a general health survey, the capacity to evaluate the impact of con- founding variables was somewhat limited, although the extent of stratified analysis possible exceeded that of earlier general population studies because of the large sample size.

In this analysis, the association between major depression, fibromyalgia and labour force participation was examined using three different perspectives: a traditional definition of labour force participation, not working due to illness or disability and, most broadly, activity limitations. The results were broadly consistent across the various definitions, suggesting that both conditions impair functioning across a broad spectrum of occupational activities. An interesting finding was that the strength of association was stronger for fibromyalgia than for major depression. This result emphasizes the potential importance of fibromyalgia as a contributor to impairment in occupational functioning.

\section{Conclusion}

From the public health perspective, these data demonstrate that major depression and fibromyalgia frequently co-occur and, when they do, both syndromes appear to contribute to a reduced frequency of labour force participation. From the perspective of service planning, these results suggest that the availability of services addressing both problems may lead to better occupational and functional outcomes. Potentially, existing services can be more effective if they are integrated in a way that fosters the delivery of such care. Integration of cognitive-behavioural strategies for pain (see review, [24]) with those for depression, for example, may lead to intervention strategies that are useful a very high proportion of patients.

\section{List of Abbreviations \\ CCHS Canadian Community Health Survey}

CIDI Composite International Diagnostic Interview

CIDI-SFMD Composite International Diagnostic Interview Short Form for Major Depression

ICD-10 International Classification of Disease, $10^{\text {th }}$ Edition

\section{Competing interests}

Neither author has competing interest to declare. The analyses reported here are based on data collected by Statistics Canada, the Canadian Government's statistical agency. The analysis itself does not reflect the opinions of Statistics Canada.

\section{Authors' contributions}

Both AK and SP participated in conceptualization of the project, and in preparation of the research proposal. Both 
authors worked together in carrying out the analyses, interpretation of the results, and in preparation of the manuscript.

\section{Disclaimer}

The analyses reported here are based on data collected by Statistics Canada, the Canadian Government's statistical agency. The analysis itself does not reflect the opinions of Statistics Canada.

\section{Acknowledgements}

Dr. Patten is a Health Scholar with the Alberta Heritage Foundation for Medical Research and a Research Fellow with the Institute of Health Economics (Edmonton, Canada)

\section{References}

I. Nampiaparampil DE, Shmerling RH: A review of fibromyalgia. Am J Man Care 2004, 10:794-800.

2. Wolfe F, Ross K, Anderson J, Russell IJ, Hebert L: The prevalence and characteristics of fibromyalgia in the general population. Arth Rheum 1995, 38:19-28.

3. Prescott E, Kjoller M, Jacobsen S, Bulow PM, Danneskiold-Samsoe B, Kamper-Jorgensen F: Fibromyalgia in the adult Danish population: I. A prevalence study. Scand ] Rheumatol 1993, 22:233-237.

4. Makela M, Heliovaara M: Prevalence of primary fibromyalgia in the Finnish population. $\mathrm{Br}$ Med J 1991, 303:216-219.

5. White KP, Speechley M, Harth M, Ostbye T: The London Fibromyalgia Epidemiology Study: the prevalence of fibromyalgia syndrome in London, Ontario. Journal of Rheumatology 1999, 26:1570-1576.

6. Wells KB, Golding JM, Burnam MA: Psychiatric disorder in a sample of the general population with and without chronic medical conditions. Am / Psychiatry I988, I45:976-98I.

7. Moldin SO, Scheftner WA, Rice JP, Nelson E, Knesevich MA, Akiskal $\mathrm{H}$ : Association between major depressive disorder and physical illness. Psychol Med 1993, 23:755-76I.

8. Patten $S B$ : Long-term medical conditions and major depression in a Canadian population survey at waves I and 2. J Affect Disord 200I, 63:35-4I.

9. Benjamin S, Morris S, McBeth J, MacFarlane GJ, Silman AJ: The association between chronic widespread pain and mental disorder. A population-based study. Arth Rheum 2000, 43:56I-567.

10. Hudson JI, Arnold LM, Keck PE, Auchenback MB, Pope HG: Family study of fibromyalgia and affective spectrum disorder. Biol Psychiatry 2004, 56:884-89I.

11. Sayar K, Gulec H, Topbas M: Alexithymia and anger in patients with fibromyalgia. Clin Rheumatol 2004, 23:44I-448.

12. Kivimäki $M$, Leino-Arjas $P$, Virtanen $M$, Elovainio $M$, KeltikangasJärvinen L, Puttonen S, Vartia M, Burnner E, Vahtera J: Work stress and incidence of newly diagnosed fibromyalgia. Prospective cohort study. J Psychosom Res 2004, 57:417-422.

13. Goldberg RT, Pachas WN, Keith D: Relationship between traumatic events in childhood and chronic pain. Disabil Rehabil 1999, 21:23-30.

14. Arnold LM, Hess EV, Hudson JI, Welge JA, Berno SE, Keck PE: A randomized, placebo-controlled, double-blind, flexible-dose study of fluoxetine in the treatment of women with fibromyalgia. Am J Med 2002, I | 2:19|-197.

15. Montoya P, Larbig W, Braun C, Preiss H, Birbaumer N: Influence of social support and emotional context on pain processing and magnetic brain responses in fibromyalgia. Arth Rheum 2004, 1 2:4035-4044.

16. Ercolani M, Trombini G, Chattat R, Cervini C, Piergiocomi G, Salaffi F, Zeni S, Marcolongo R: Fibromyalgic syndrome: depression and abnormal illness behavior. Multicenter investigation. Psychother Psychosom 1994, 61:178-186.

17. Alfici S, Sigal M, Landau M: Primary fibromyalgia syndrome - a variant of depressive disorder? Psychother Psychosom 1989, 5I:I56-I6I.
18. Hudson Jl, Goldenberg DL, Pope HG, Keck PE, Schlesinger L: Comorbidity of fibromyalgia with medical and psychiatric disorders. Am J Med 1992, 92:363-367.

19. Van Houdenhove B, Egle UT: Fibromyalgia: a Stress Disorder? Piecing the biopsychosocial puzzle together. Psychother Psychosom 2004, 73:267-275.

20. Aaron LA, Bradley LA, Alarcón GS, Alexander RW, Triana-Alexander M, Martin MY, Alberts KR: Psychiatric diagnoses in patients with fibromyalgia are related to health care-seeking behavior rather than to illness. Arth Rheum 1996, 39:436-445.

21. Robinson RL, Birnbaum HG, Morley MA, Sisitsky T, Greenberg PE, Wolfe F: Depression and fibromyalgia: treatment and cost when diagnosed separately or concurrently. J Rheumatol 2004, 31:162I-1629.

22. Canada S: Canadian Community Health Survey (CCHS) Cycle I.I. Derived Variables (DV) Specifications. [http:/I www.statcan.ca/english/sdds/document $/$

3226_D5_T9_V2_E.pdf]. Ottawa, Canada; 2002.

23. Bair MJ, Robinson RL, Katon W, Kroenke K: Depression and pain comorbidity. A literature revew. Arch Intern Med 2003, 163:2433-2445.

24. Williams DA: Psychological and behavioural therapies in fibromyalgia and related syndromes. Best Pract Res Clin Rheum 2003, 17:649-665.

\section{Pre-publication history}

The pre-publication history for this paper can be accessed here:

http://www.biomedcentral.com/1471-2474/7/4/prepub
Publish with Biomed Central and every scientist can read your work free of charge

"BioMed Central will be the most significant development for disseminating the results of biomedical research in our lifetime. "

Sir Paul Nurse, Cancer Research UK

Your research papers will be:

- available free of charge to the entire biomedical community

- peer reviewed and published immediately upon acceptance

- cited in PubMed and archived on PubMed Central

- yours - you keep the copyright

Submit your manuscript here:

http://www.biomedcentral.com/info/publishing_adv.asp
BioMedcentral 